\title{
Clinical significance of syndecan- 1 and versican expression in human epithelial ovarian cancer
}

\author{
TOMOYUKI KUSUMOTO, JUNICHI KODAMA, NORIKO SEKI, \\ KEIICHIRO NAKAMURA, ATSUSHI HONGO and YUJI HIRAMATSU
}

Department of Obstetrics and Gynecology, Okayama University Graduate School of Medicine, Dentistry and Pharmaceutical Sciences, 2-5-1 Shikata-cho, Okayama 700-8558, Japan

Received August 21, 2009; Accepted October 9, 2009

DOI: 10.3892/or_00000715

\begin{abstract}
Proteoglycans are ubiquitous components of the extracellular matrix and cell surface, and may mediate tumor progression and metastasis. The aim of this study was to evaluate the expression of syndecan- 1 and versican in epithelial ovarian cancer. We immunohistochemically evaluated the expression of syndecan-1 and versican in 111 patients with epithelial ovarian cancer, and analyzed the correlation of this expression with various observed clinicopathological features, including patient outcome. There is a significant correlation between primary and metastatic sites with respect to syndecan-1 and versican expression. Epithelial syndecan-1 expression was significantly lower in patients with advanced disease. Epithelial versican expression was significantly higher in patients with early disease, especially in clear cell adenocarcinoma patients. Stromal syndecan-1 and versican expression was significantly higher in patients with advanced disease. Multivariate analysis showed that negative epithelial syndecan-1 expression was an independent prognostic factor for progression-free survival. Stromal syndecan-1 and versican co-expression was of borderline significance for progression-free and overall survival. Loss of epithelial syndecan-1 expression and induction of stromal syndecan-1 and versican expression may be associated with tumor progression in epithelial ovarian cancer. Syndecan-1 and versican expression status can serve as an indicator of prognosis in patients with epithelial ovarian cancer.
\end{abstract}

\section{Introduction}

It is well known that the tumor environment is one of the major factors that determines the behavior of malignant cells.

Correspondence to: Dr Junichi Kodama, Department of Obstetrics and Gynecology, Okayama University Graduate School of Medicine, Dentistry and Pharmaceutical Sciences, 2-5-1 Shikata-cho, Kita-ku, Okayama 700-8558, Japan

E-mail: kodama@cc.okayama-u.ac.jp

Key words: epithelial ovarian cancer, syndecan-1, versican, prognosis
Proteoglycans are ubiquitous components of the extracellular matrix (ECM) and cell surface. Remodeling of the ECM through altered expression of molecules involved in cell-tocell and cell-to-matrix interactions is essential for local tumor invasion and metastasis (1).

Heparan sulfate proteoglycans (HSPGs) consist of a core protein to which heparan sulfate glycosaminoglycan (HSGAG) chains are covalently attached. These molecules are classified into several families according to the amino acid sequence of the core protein, and examples include syndecans and perlecans $(2,3)$. Syndecans, which are cell-surface HSPGs, participate in cell-cell and cell-ECM interactions $(2,4)$. To date, 4 members of the syndecan family have been identified, all having homologous transmembrane and cytoplasmic domains but differing extracellular domains (5). Syndecan-1 (CD138) is the most well characterized member of the family and its expression is localized entirely in epithelial cells, with stratified squamous epithelia showing the most abundant expression (6). Decreased expression of syndecan-1 has been reported to be correlated with increased tumorigenicity and tumor invasion (7-9). Syndecan-1 binds to various ECM components, such as collagen, fibronectin, thrombospondin, and tenascin, via the HS-GAG chains and most of its biological functions are considered to be associated with this process (2-4). It also binds to members of the heparin-binding growth factor family such as the basic fibroblast growth factor (bFGF), which is the best-studied example; hepatocyte growth factor (HGF); a splice variant of platelet-derived growth factor (PDGF); heparin-binding epidermal growth factor (EGF); vascular endothelial growth factor (VEGF); neuregulins; and others (4). The loss of epithelial syndecan-1 expression has been associated with poor prognosis in some forms of cancer (10-17). Recently, stromal syndecan-1 expression was found to be correlated with a devastating clinical course in several kinds of cancers (11,17-19).

Versican is a member of the large aggregating chondroitin sulfate proteoglycan (CSPG) family (20). Structurally, versican is composed of an N-terminal G1 domain, a GAG attachment region, and a C-terminal G3 domain. Alternative splicing generates at least 4 isoforms of versican, named $\mathrm{V} 0$, V1, V2 and V3 (21-23). V0, the largest isoform, contains 2 GAG-binding regions called the CS $\alpha$ and CSß domains. The $\mathrm{V} 1$ isoform contains a CSß domain, and the V2 isoform 
contains a CS $\alpha$ domain. The V3 isoform is composed solely of the G1 and G3 domains, lacking any potential GAG attachment sites. Versican is highly expressed in the early stages of tissue development, and its expression decreases after tissue maturation. Its expression is also elevated during wound repair and tumor growth (24-26). An increase in versican expression in the ECM facilitates local tumor invasion and metastasis by decreasing the cell-ECM adhesion (27). In fact, it has been demonstrated that versican expression is related to tumor progression in some types of malignant tumors (28-32).

A few studies have investigated syndecan-1 and versican expression in epithelial ovarian cancers. Here, we investigated the expression of syndecan-1 and versican in 111 patients with epithelial ovarian cancer. We then analyzed the correlation of this expression with various clinicopathological features, including patient outcome.

\section{Patients and methods}

Patients and tissue samples. In this study, we examined 111 patients with epithelial ovarian cancer. These patients underwent laparotomy at the Department of Obstetrics and Gynecology of Okayama University Hospital from 1992 to 2003. Tumor specimens were obtained at the time of surgery and were immediately fixed in $10 \%$ neutral-buffered formalin and embedded in paraffin. In 12 of the 111 patients, tumor specimens were only available at the peritoneal metastatic site. Informed consent was obtained from each patient before sample collection. Histological cell typing was performed, and on the basis of the World Health Organization (WHO) classification, 66 tumors were identified as serous adenocarcinoma, 23 as endometrioid adenocarcinoma, 15 as clear cell adenocarcinoma, 6 as mucinous adenocarcinoma, and 1 as other epithelial adenocarcinoma. Surgical staging was assessed by the International Federation of Gynecology and Obstetrics (FIGO) system and it was found that 35 patients had stage I; 12, stage II; 55, stage III; and 9, stage IV cancer. The median age at the time of surgery was 54 years (range, 28-84 years). All patients underwent primary debulking surgery and received postoperative platinum-based chemotherapy. Interval debulking surgery was performed for 37 patients. Progression-free and overall survival rates were defined as the interval from the initial surgery to clinically or radiologically proven recurrence and death, respectively. The median duration of follow-up was 35 months (range, 2-160 months).

Immunohistochemical and staining evaluation. We placed 4- $\mu$ m-thick sections obtained from several representative areas of the tumor specimens on glass slides and immunostained them according to the labeled streptavidin-biotin (LSAB) method by using the Dako LSAB kit (Dako North America, Inc., CA, USA). Briefly, the slides were dewaxed in xylene and rehydrated in an alcohol series. Subsequently, antigen retrieval was performed in a microwave oven in $10 \mathrm{mM}$ citric acid buffer ( $\mathrm{pH}$ 6.0) for $3 \times 10 \mathrm{~min}$. The sections were incubated with $0.3 \%$ hydrogen peroxide to block endogenous peroxidase activity, followed by incubation with normal horse serum for $5 \mathrm{~min}$ at room temperature. The sections were immunostained by incubating with 1:100 diluted mouse monoclonal anti-human syndecan-1 core protein (clone, B-B4; Immunotech, Marseille, France) and 1:500 diluted mouse monoclonal anti-human versican (clone, 2B1; Seikagaku Corp., Ltd., Tokyo, Japan) for $2 \mathrm{~h}$ at room temperature. Next, the sections were incubated with biotinylated goat antimouse immunoglobulin for $20 \mathrm{~min}$ followed by incubation with peroxidase-conjugated streptavidin for $20 \mathrm{~min}$ and with $0.05 \%$ 3,3'-diaminobenzidine tetrahydrochloride (Wako Pure Chemical Industries, Ltd., Osaka, Japan) containing hydrogen peroxide for $10 \mathrm{~min}$. Finally, the slides were counterstained with Mayer's hematoxylin and mounted in an aqueous mounting medium. At each step, the slides were washed carefully in phosphate-buffered saline $(\mathrm{pH}$ 7.4). For the negative control, we incubated the sections with normal mouse serum at a concentration of $10 \mu \mathrm{g} / \mathrm{ml}$. For the positive control, we used normal cervical squamous epithelium for syndecan- 1 analysis and the walls of the blood vessels in the myometrium for versican analysis.

Staining evaluation. Syndecan-1 immunoreactivity in stromal cells was expressed as a score on the basis of the percentage of syndecan-1-positive cells as follows: strong (2), >50\% of the cells stained; moderate (1), $10-50 \%$ of the cells stained; and weak $(0),<10 \%$ of the cells stained. Versican immunoreactivity in the stroma was expressed as a score on the basis of the percentage area of versican-positive stroma in the periand intra-tumoral regions as follows: strong (2), $>50 \%$ of the stroma stained; moderate (1), $10-50 \%$ of the stroma stained; and weak $(0),<10 \%$ of the stroma stained. Any specimen showing cancer cell-associated syndecan-1 or versican staining was considered as positive (score, 1). Microscopic analyses were independently conducted by two of the authors who had no prior knowledge of the clinical data. In questionable cases, we made the final decision by using a conference microscope.

Statistical analyses. Mann-Whitney U-test was used to examine the association between the clinicopathological factors and syndecan-1 or versican expression. The survival rates were calculated by the Kaplan-Meier method, and the differences between the survival curves were examined using the log-rank test. The factors that were found to be significant were then analyzed by the stepwise Cox's multivariate proportional hazard model to determine their prognostic value. These analyses were performed by utilizing the StatView 5.0 software (Abacus Concepts, Inc., CA, USA). $\mathrm{P}$-values $<0.05$ were considered to be statistically significant.

\section{Results}

Syndecan-1 and versican expression in epithelial ovarian cancer. Figs. 1 and 2 illustrate the representative immunostaining patterns of syndecan-1 and versican, respectively, in epithelial ovarian cancer. In 16 cases, we analyzed the correlation of syndecan-1 and versican expression at the primary and peritoneal metastatic sites. A significant correlation was found between the primary and metastatic sites for syndecan-1 and versican expression both in the epithelium and in the tumor stroma (Table I). 

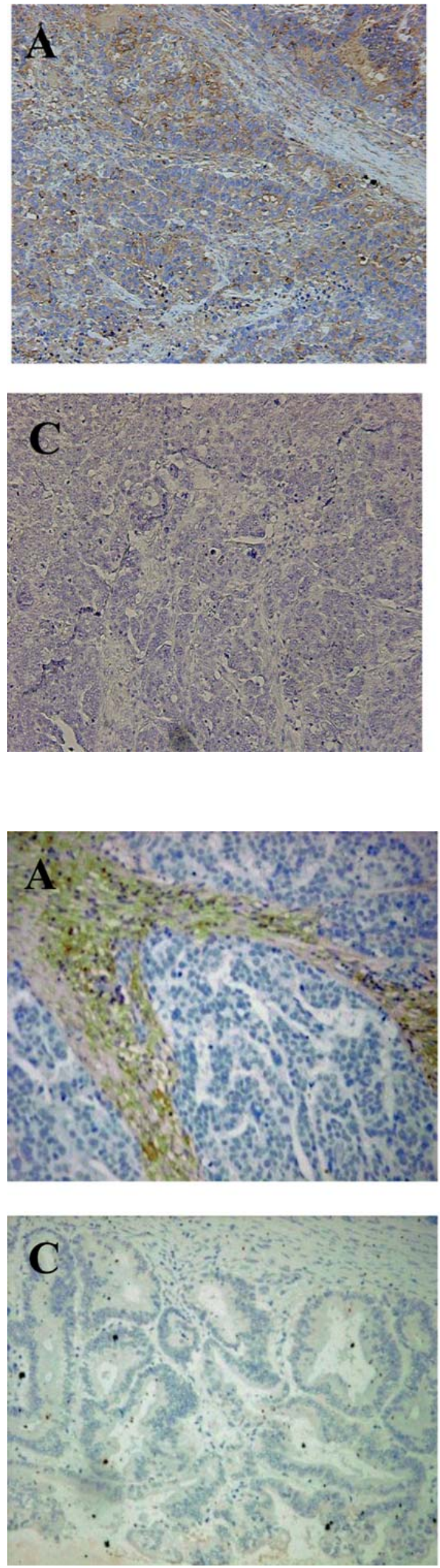

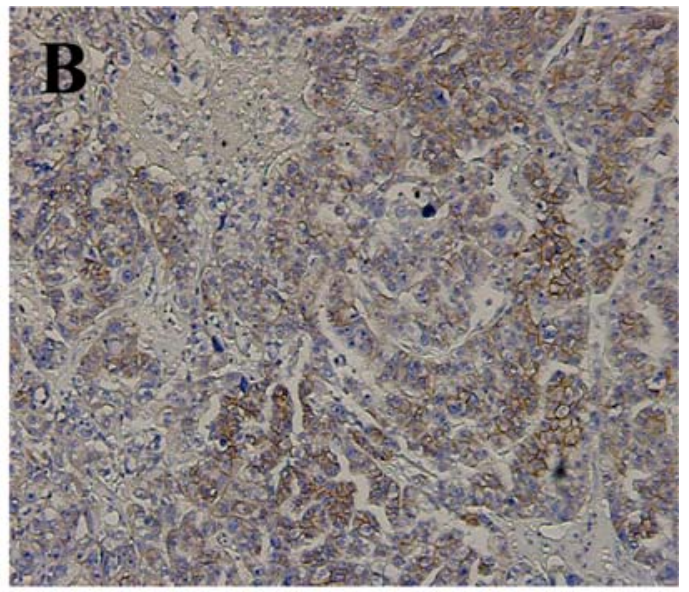

Figure 1. Immunohistochemical staining of syndecan-1 in epithelial ovarian cancer by using the anti-human syndecan-1 core protein B-B4. (A) Positive epithelial cell and moderate stromal cell staining. (B) Positive epithelial cell and weak stromal cell staining. (C) Negative epithelial cell and weak stromal cell staining.

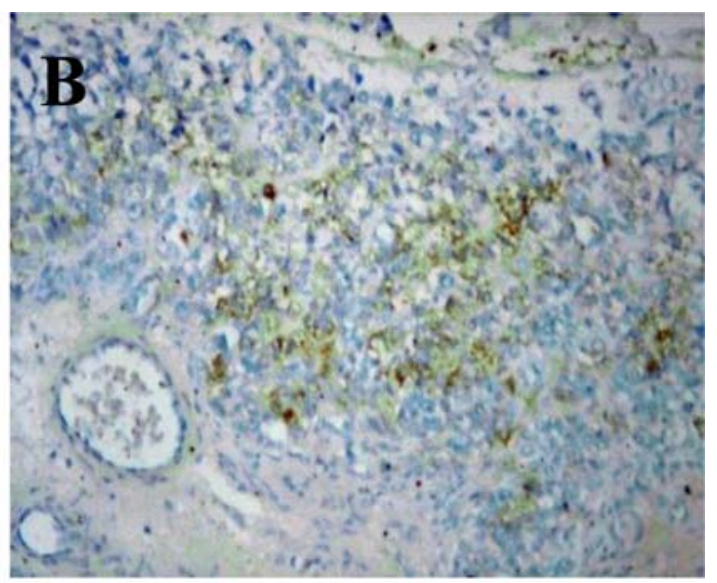

Figure 2. Immunohistochemical staining of versican in epithelial ovarian cancer by using the anti-human versican protein 2B1. (A) Negative epithelial cell and strong stromal staining. (B) Positive epithelial cell and weak stromal staining. (C) Negative epithelial cell and weak stromal staining. 
Table I. Correlation of syndecan-1 and versican expression in primary and metastatic sites.

Epithelial Syndecan-1 expression index

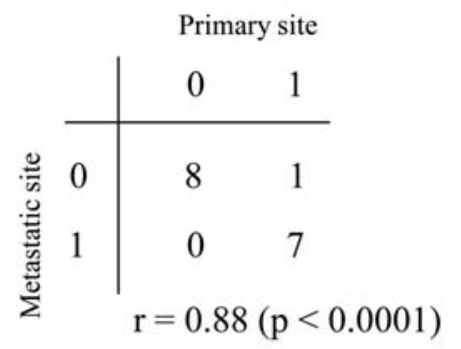

Stromal Syndecan-1 expression index

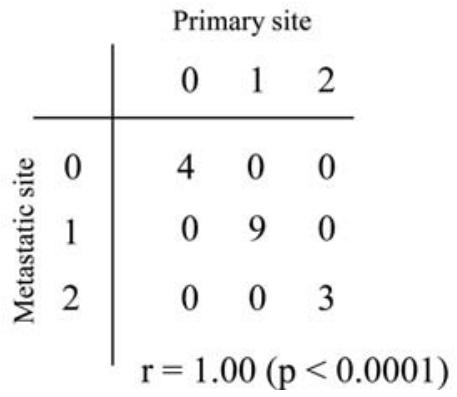

Epithelial Versican expression index

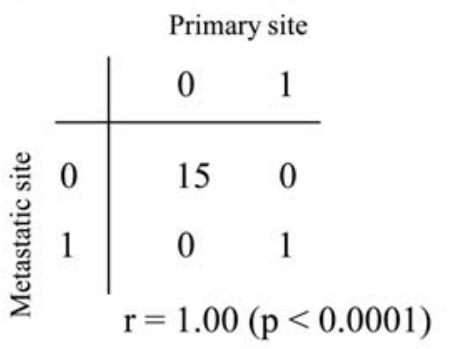

Stromal Versican expression index Primary site

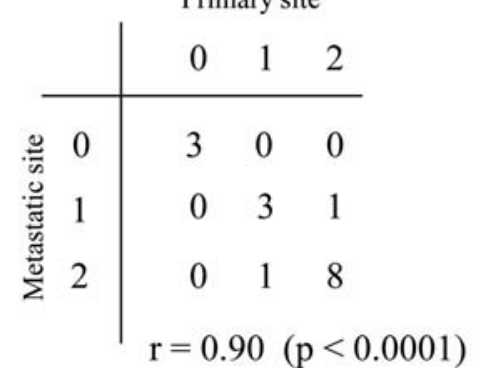

Epithelial and stromal syndecan-1 expression. The association between syndecan-1 expression and clinicopathological factors is shown in Table II. Epithelial syndecan-1 was expressed in 58 tumors $(52 \%)$ and not expressed in 53 tumors (48\%). The score for epithelial syndecan-1 expression was significantly lower in patients with advanced stage cancer $(p=0.01)$, cancer of the serous histological subtype $(\mathrm{p}=0.03)$, and positive lymph node metastasis $(\mathrm{p}=0.002)$. Strong stromal syndecan-1 staining was seen in 18 tumors (16\%), moderate staining in 41 tumors $(37 \%)$ and weak staining in 52 tumors (47\%). The score for stromal syndecan-1 expression was significantly higher in patients with advanced stage cancer $(\mathrm{p}<0.0001)$, cancer of the serous histological subtype $(\mathrm{p}<0.0001)$, massive ascites $(\mathrm{p}=0.02)$, positive peritoneal cytology $(\mathrm{p}=0.0002)$, suboptimal cytoreduction $(\mathrm{p}<0.0001)$ and lymph node metastasis $(\mathrm{p}=0.01)$. There was no significant association between epithelial and stromal syndecan-1 expression (data not shown).

Epithelial and stromal versican expression. The association between versican expression and clinicopathological factors is shown in Table II. Epithelial versican was expressed in 19 tumors $(17 \%)$ and not expressed in 92 tumors $(83 \%)$. The score for epithelial versican expression was significantly lower in the elderly $(\mathrm{p}=0.04)$, and in patients with advanced stage cancer $(\mathrm{p}=0.0004)$, cancer of the serous histological subtype $(\mathrm{p}=0.0002)$, massive ascites $(\mathrm{p}=0.03)$, positive peritoneal cytology $(\mathrm{p}=0.01)$, suboptimal cytoreduction $(\mathrm{p}=0.01)$, and lymph node metastasis $(\mathrm{p}=0.01)$. It is noteworthy that in 11 of the $15(73 \%)$ cases of clear cell adenocarcinoma, epithelial versican was expressed. The score for stromal versican expression was significantly higher in patients with advanced stage cancer $(\mathrm{p}=0.0003)$, cancer of the serous histological subtype $(\mathrm{p}=0.002)$, massive ascites $(\mathrm{p}=0.02)$, positive peritoneal cytology ( $\mathrm{p}=0.002)$, and suboptimal cytoreduction $(\mathrm{p}=0.0003)$. No significant association was noted between epithelial and stromal versican expression (data not shown).

Univariate survival analysis. Figs. 3 and 4 present the effect of the syndecan- 1 expression status on the progression-free and overall survival curves for 111 patients with epithelial ovarian cancer. The progression-free survival rates of patients with epithelial syndecan-1 expression were significantly higher than those of patients with negative epithelial syndecan-1 expression $(\mathrm{p}=0.025)$. The progression-free and overall survival rates of patients with high stromal syndecan-1 expression were significantly lower than those of patients with low stromal syndecan- 1 expression $(\mathrm{p}=0.001$ and $\mathrm{p}=0.022$, respectively). Figs. 5 and 6 present the effect of the versican expression status on the progression-free and overall survival curves. The progression-free and overall survival rates of patients with epithelial versican expression were significantly higher than those of patients with negative epithelial versican expression $(p=0.010$ and $p=0.028$, respectively). The progression-free and overall survival rates of patients with high stromal versican expression were significantly lower than those of patients with low stromal versican expression ( $p=0.0004$ and $p=0.043$, respectively). The results of the univariate survival analyses of the other variables are shown in Table III.

Multivariate survival analysis. Multivariate analysis showed that massive ascites was the strongest independent prognostic factor for progression-free survival; this was followed by the FIGO stage and negative epithelial syndecan-1 expression 
Table II. Association between syndecan-1 and versican expression and clinicopathological factors in epithelial ovarian cancer.

\begin{tabular}{|c|c|c|c|c|c|c|c|c|c|}
\hline Variables & $\begin{array}{l}\text { No. of } \\
\text { cases }\end{array}$ & $\begin{array}{c}\text { E-syndecan-1 } \\
(\text { mean } \pm \mathrm{SE})\end{array}$ & P-value ${ }^{a}$ & $\begin{array}{c}\text { S-syndecan-1 } \\
(\text { mean } \pm \mathrm{SE})\end{array}$ & P-value ${ }^{a}$ & $\begin{array}{c}\text { E-versican } \\
(\text { mean } \pm \mathrm{SE})\end{array}$ & P-value & $\begin{array}{c}\text { S-versican } \\
(\text { mean } \pm \text { SE) }\end{array}$ & P-value \\
\hline Age (years) & & & 0.12 & & 0.74 & & 0.04 & & 0.30 \\
\hline$<60$ & 71 & $0.58 \pm 0.06$ & & $0.68 \pm 0.09$ & & $0.23 \pm 0.05$ & & $0.85 \pm 0.10$ & \\
\hline$\geq 60$ & 40 & $0.43 \pm 0.08$ & & $0.73 \pm 0.12$ & & $0.08 \pm 0.04$ & & $1.03 \pm 0.14$ & \\
\hline FIGO stage & & & 0.01 & & $<0.0001$ & & 0.0004 & & 0.0003 \\
\hline $\mathrm{I}+\mathrm{II}$ & 47 & $0.66 \pm 0.07$ & & $0.34 \pm 0.09$ & & $0.32 \pm 0.07$ & & $0.55 \pm 0.10$ & \\
\hline $\mathrm{III}+\mathrm{IV}$ & & $0.43 \pm 0.06$ & & $0.95 \pm 0.09$ & & $0.06 \pm 0.03$ & & $1.17 \pm 0.11$ & \\
\hline $\begin{array}{l}\text { Histological } \\
\text { subtype }\end{array}$ & & & 0.03 & & $<0.0001$ & & 0.0002 & & 0.002 \\
\hline Serous & 66 & $0.44 \pm 0.06$ & & $0.92 \pm 0.09$ & & $0.06 \pm 0.03$ & & $1.12 \pm 0.11$ & \\
\hline Non-serous & 45 & $0.64 \pm 0.07$ & & $0.36 \pm 0.09$ & & $0.33 \pm 0.07$ & & $0.60 \pm 0.12$ & \\
\hline $\begin{array}{l}\text { Amount of } \\
\text { ascites }\end{array}$ & & & 0.76 & & 0.02 & & 0.03 & & 0.02 \\
\hline$<1000 \mathrm{ml}$ & 84 & $0.54 \pm 0.05$ & & $0.61 \pm 0.08$ & & $0.21 \pm 0.05$ & & $0.80 \pm 0.09$ & \\
\hline$\geq 1000 \mathrm{ml}$ & 27 & $0.48 \pm 0.10$ & & $0.96 \pm 0.14$ & & $0.04 \pm 0.04$ & & $1.26 \pm 0.17$ & \\
\hline $\begin{array}{l}\text { Peritoneal } \\
\text { cytology }\end{array}$ & & & 0.88 & & 0.0002 & & 0.01 & & 0.002 \\
\hline Negative & 39 & $0.51 \pm 0.08$ & & $0.36 \pm 0.10$ & & $0.31 \pm 0.07$ & & $0.56 \pm 0.12$ & \\
\hline Positive & 72 & $0.53 \pm 0.06$ & & $0.88 \pm 0.09$ & & $0.10 \pm 0.04$ & & $1.10 \pm 0.10$ & \\
\hline $\begin{array}{l}\text { Diameter of } \\
\text { residual tumor }\end{array}$ & & & 0.43 & & $<0.0001$ & & 0.01 & & 0.0003 \\
\hline$<1 \mathrm{~cm}$ & 65 & $0.55 \pm 0.06$ & & $0.45 \pm 0.08$ & & $0.28 \pm 0.06$ & & $0.69 \pm 0.10$ & \\
\hline$\geq 1 \mathrm{~cm}$ & 46 & $0.48 \pm 0.07$ & & $1.04 \pm 0.11$ & & $0.02 \pm 0.02$ & & $1.22 \pm 0.12$ & \\
\hline $\begin{array}{l}\text { Lymph node } \\
\text { status }^{\text {b }}\end{array}$ & & & 0.002 & & 0.01 & & 0.01 & & 0.21 \\
\hline Negative & 75 & $0.63 \pm 0.10$ & & $0.57 \pm 0.08$ & & $0.24 \pm 0.05$ & & $0.84 \pm 0.14$ & \\
\hline Positive & 36 & $0.31 \pm 0.14$ & & $0.94 \pm 0.12$ & & $0.03 \pm 0.03$ & & $1.06 \pm 0.19$ & \\
\hline
\end{tabular}

aMann-Whitney U-test; E, epithelial; S, stromal; bymph node status was assessed by CT imaging in 47 patients.

A

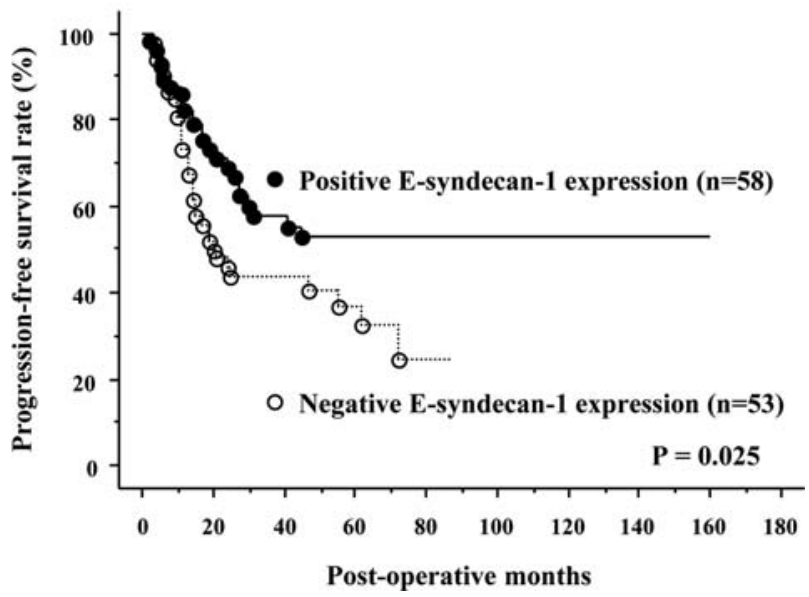

B

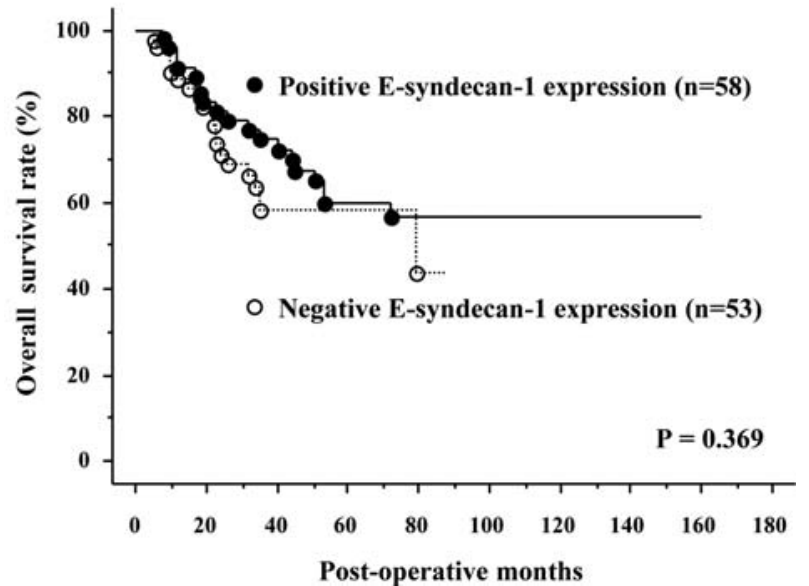

Figure 3. Effect of epithelial (E) syndecan-1 expression status on the (A) progression-free and (B) overall survival curves of 111 patients with epithelial ovarian cancer. 
A

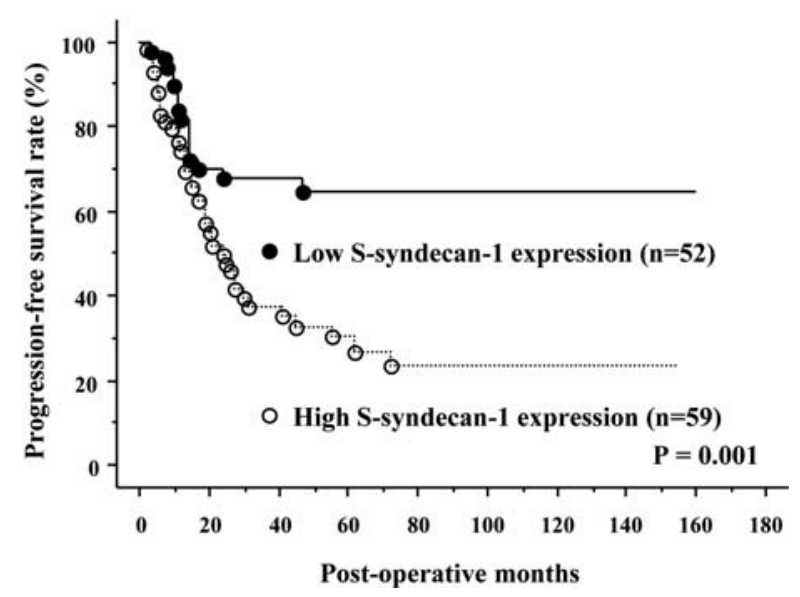

B

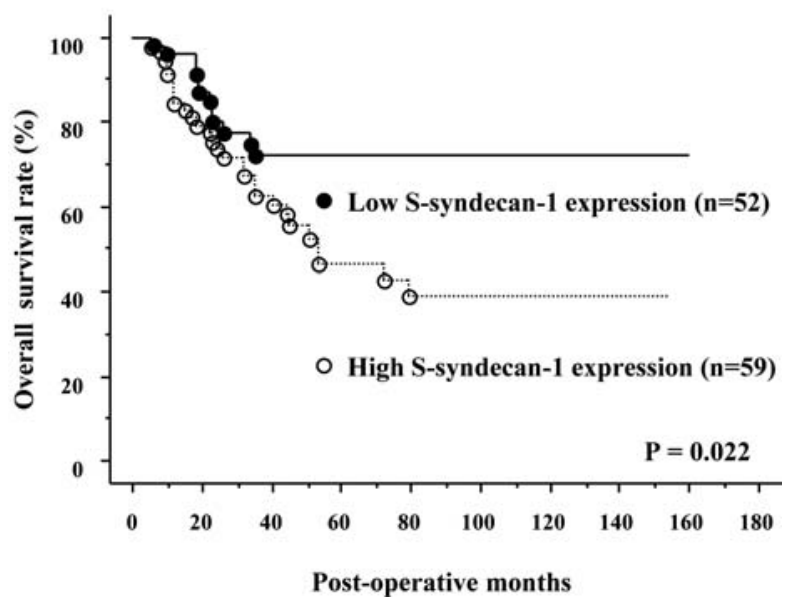

Figure 4. Effect of stromal (S) syndecan-1 expression status on (A) progression-free and (B) overall survival curves of 111 patients with epithelial ovarian cancer. Score 0 , low stromal expression; score 1-2, high stromal expression.

A

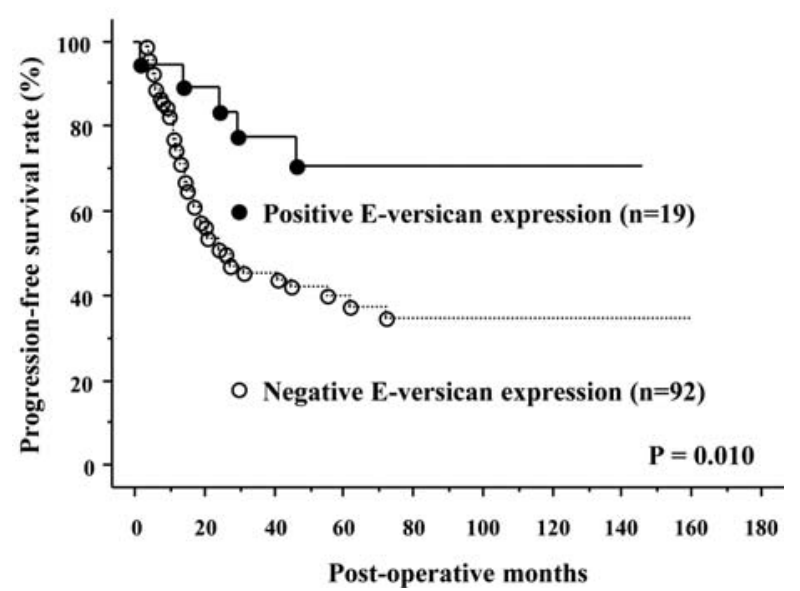

B

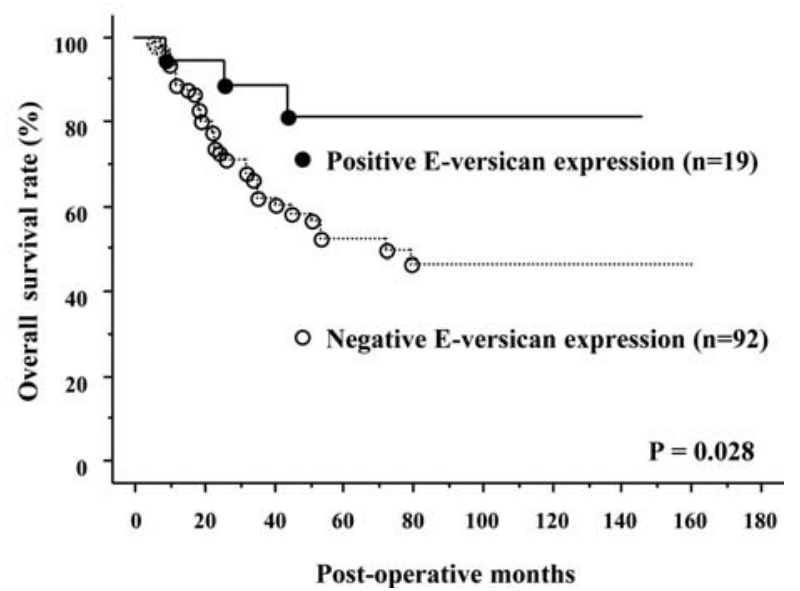

Figure 5. Effect of epithelial (E) versican expression status on (A) progression-free and (B) overall survival curves of 111 patients with epithelial ovarian cancer.

A

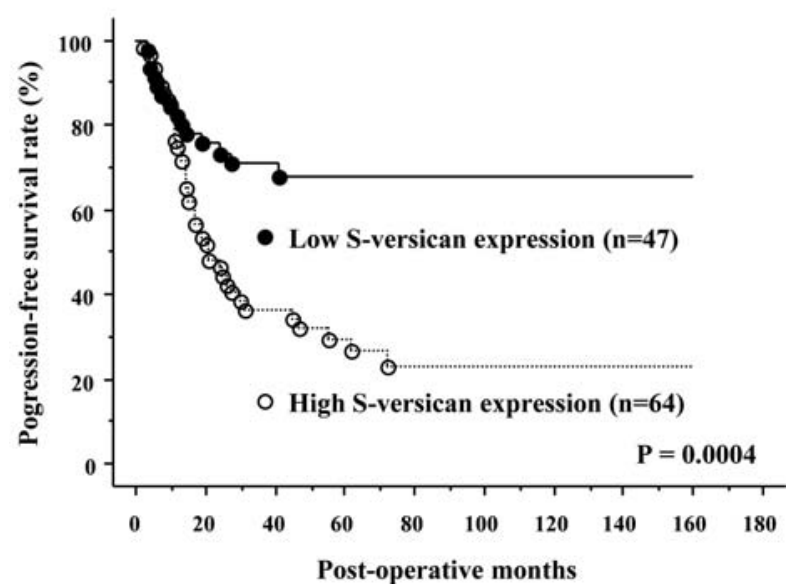

B

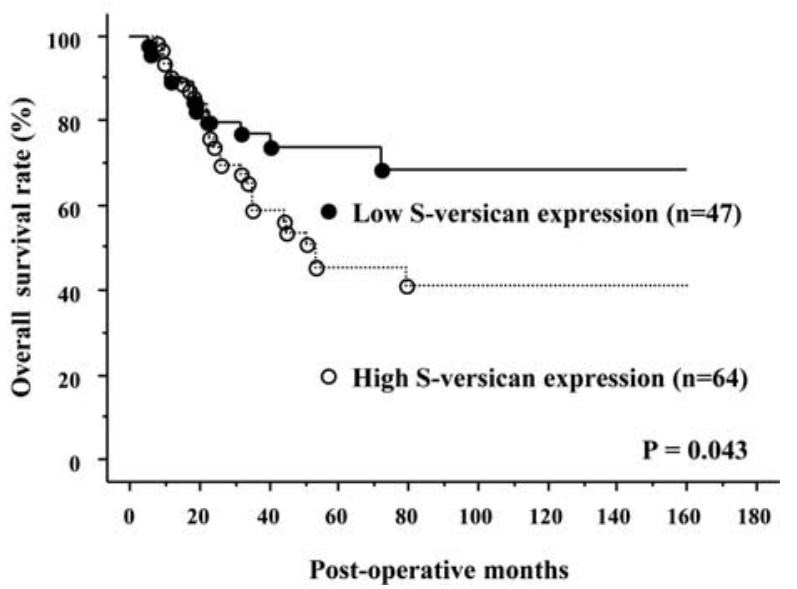

Figure 6. Effect of stromal (S) versican expression status on (A) progression-free and (B) overall survival curves of 111 patients with epithelial ovarian cancer. Score 0, low stromal expression; score 1-2, high stromal expression. 
Table III. Progression-free and overall survival analyses of prognostic factors using the log-rank test.

\begin{tabular}{|c|c|c|c|c|c|}
\hline \multirow[b]{2}{*}{ Variables } & \multirow[b]{2}{*}{ No. } & \multicolumn{2}{|c|}{ Estimated 5-year PFS } & \multicolumn{2}{|c|}{ Estimated 5-year OS } \\
\hline & & $(\%)$ & P-value ${ }^{a}$ & $(\%)$ & P-value ${ }^{a}$ \\
\hline \multicolumn{6}{|l|}{ Age (years) } \\
\hline$<60$ & 71 & 59.4 & 0.0001 & 67.3 & 0.013 \\
\hline$\geq 60$ & 40 & 22.8 & & 42.5 & \\
\hline \multicolumn{6}{|l|}{ FIGO stage } \\
\hline I+II & 47 & 88.2 & $<0.0001$ & 95.3 & $<0.0001$ \\
\hline $\mathrm{III}+\mathrm{IV}$ & 64 & 17.6 & & 33.1 & \\
\hline \multicolumn{6}{|c|}{ Histological subtype } \\
\hline Serous & 66 & 27.8 & $<0.0001$ & 44.6 & $<0.003$ \\
\hline Non-serous & 45 & 73.8 & & 79.2 & \\
\hline \multicolumn{6}{|c|}{ Amount of ascites } \\
\hline$<1000 \mathrm{ml}$ & 84 & 56.9 & $<0.0001$ & 73.8 & $<0.0001$ \\
\hline$\geq 1000 \mathrm{ml}$ & 27 & 9.3 & & 13.2 & \\
\hline \multicolumn{6}{|c|}{ Peritoneal cytology } \\
\hline Negative & 39 & 79.0 & $<0.0001$ & 95.7 & $<0.0001$ \\
\hline Positive & 72 & 29.4 & & 40.0 & \\
\hline \multicolumn{6}{|c|}{$\begin{array}{l}\text { Diameter of residual } \\
\text { tumor }\end{array}$} \\
\hline$<1 \mathrm{~cm}$ & 65 & 63.9 & $<0.0001$ & 76.8 & $<0.0001$ \\
\hline$\geq 1 \mathrm{~cm}$ & 46 & 21.1 & & 32.7 & \\
\hline \multicolumn{6}{|c|}{ Lymph node status } \\
\hline negative & 75 & 53.9 & 0.002 & 67.8 & 0.002 \\
\hline positive & 36 & 28.4 & & 39.7 & \\
\hline \multicolumn{6}{|c|}{ Epithelial syndecan-1 } \\
\hline Negative & 53 & 37.0 & 0.025 & 58.4 & 0.369 \\
\hline Positive & 58 & 52.7 & & 59.8 & \\
\hline \multicolumn{6}{|c|}{ Stromal syndecan-1 } \\
\hline Low $(0)$ & 52 & 64.5 & 0.001 & 72.2 & 0.022 \\
\hline High (1 or 2$)$ & 59 & 30.4 & & 46.7 & \\
\hline \multicolumn{6}{|c|}{ Epithelial versican } \\
\hline Negative & 92 & 40.0 & 0.010 & 52.5 & 0.028 \\
\hline Positive & 19 & 70.5 & & 81.4 & \\
\hline \multicolumn{6}{|l|}{ Stromal versican } \\
\hline Low $(0)$ & 47 & 67.8 & 0.0004 & 74.0 & 0.043 \\
\hline High (1 or 2$)$ & 64 & 29.2 & & 45.6 & \\
\hline
\end{tabular}

${ }^{a}$ Kaplan-Meier test; PFS, progression-free survival; OS, overall survival; FIGO, International Federation of Gynecology and Obstetrics.

(Table IV). In addition, massive ascites was also the strongest independent prognostic factor for overall survival, followed by the FIGO stage and positive peritoneal cytology (Table IV). Stromal syndecan-1 and versican co-expression was of borderline significance for progression-free and overall survival rates $(\mathrm{p}=0.076$ and $\mathrm{p}=0.059$, respectively).

\section{Discussion}

Invasion and metastasis are characteristics of malignant solid tumors, and many mechanisms are involved in these processes. Cell adhesion molecules, such as integrins, cadherins, and cell-surface HSPGs, and ECM components are particularly 
Table IV. Prognostic factors for progression-free and overall survival selected by Cox's multivariate proportional hazard model analysis.

\begin{tabular}{lccc}
\hline & $\begin{array}{c}\text { Hazard } \\
\text { ratio }\end{array}$ & $95 \%$ CI & $\begin{array}{c}\text { Cox's test } \\
\text { P-value }\end{array}$ \\
\hline $\begin{array}{l}\text { Progression-free survival } \\
\text { Massive ascites }\end{array}$ & 2.65 & $1.43-4.85$ & 0.002 \\
FIGO stage & 5.85 & $1.68-20.41$ & 0.005 \\
Negative epithelial & 1.81 & $1.00-3.25$ & 0.049 \\
Syndecan-1 & & & \\
Overall survival & & & \\
Massive ascites & 2.72 & $1.29-5.75$ & 0.009 \\
FIGO stage & 8.20 & $1.45-45.45$ & 0.017 \\
Peritoneal cytology & 9.01 & $11.3-71.43$ & 0.038 \\
\hline
\end{tabular}

important in the regulation of cell differentiation, morphology and migration (33-35). In this study, we analyzed syndecan-1 and versican expression in a series of human epithelial ovarian cancer specimens.

Epithelial syndecan- 1 expression was observed in $52 \%$ of the patients with epithelial ovarian cancer, and it decreased with advanced stage cancer, serous histology and lymph node metastasis. Davies et al also reported that epithelial syndecan-1 was expressed in $40 \%$ of the cases of epithelial ovarian cancer, although they did not mention the association between epithelial syndecan-1 expression and clinicopathological factors (36). Reduced expression of epithelial syndecan-1 in colorectal, gastric and laryngeal cancers; hepatocellular carcinoma; head and neck carcinoma; cholangiocarcinoma; malignant mesothelioma; and endometrial cancer has been reported to be associated with dedifferentiation of cancer cells or increasing metastatic potential $(10-13,15-17)$. These results suggest that epithelial syndecan- 1 is an important molecule in the regulation of cell proliferation and differentiation in a wide range of tumors. Indeed, it has been shown that the suppression of endogenous syndecan-1 expression in epithelial cells by transfection with syndecan- 1 antisense cDNA results in a loss of the epithelial characteristics of the parental cells. Further, the parental cells elongate and become fusiform, they can invade and migrate within collagen gels, and become capable of anchorage-independent growth. The transformed fusiform cells show a rearrangement of B1-integrins, markedly reduced E-cadherin expression, and altered disposition of the actin cytoskeleton (37).

Stromal syndecan-1 expression was first demonstrated by Stanley et al in infiltrating breast carcinoma (38). They speculated that because syndecan-1 interacts with heparinbinding growth factors such as FGF-2, accumulation of syndecan-1 within the tumor stroma may contribute to the extensive angiogenesis and stromal proliferation characteristic of infiltrating breast carcinoma. In the present study, we have demonstrated that stromal expression of syndecan-1 is present in advanced tumors. Maeda et al have reported that syndecan-1 expression in stromal cells promotes carcinoma cell growth (39). They speculated that syndecan-1 expression in stromal fibroblasts creates a favorable microenvironment for accelerated tumor cell growth by storing and presenting growth factors to the carcinoma cells as many epithelial mitogens, including FGFs, HGF and heparin-binding EGF, bind to syndecan-1 HS-GAG chains.

We demonstrated that the overexpression of stromal versican was associated with advanced stage cancer, cancer of the serous histological subtype, massive ascites, positive peritoneal cytology, and large residual tumors. Our previous studies showed that the overexpression of stromal versican in endometrial and cervical cancer is associated with tumor progression $(32,40)$. These results suggest that stromal versican is an important molecule in the progression of gynecological malignant tumors. Indeed, it has been shown that the versican G1 domain can enhance cell proliferation and reduce cell adhesion in different cell types $(41,42)$, and the versican G3 domain enhances tumor growth and angiogenesis (43).

In the present study, versican was mainly present in the peri-tumoral stroma; however, tumor cell-associated versican was also observed in $17 \%$ of the tumors. In fact, Casey et al reported that versican mRNA was detected in lower amounts in the ovarian carcinoma cells NIH:OVCAR5 (44). Although versican is probably synthesized mostly in tumor stroma by fibroblasts, malignant cells can also synthesize versican. The occurrence of versican-positive tumor cells was significantly higher in patients with early stage cancer and cancer with the non-serous histology, especially clear cell histology. This is in accordance with the results reported by Voutilainen et al (45). Interestingly, our previous studies showed that epithelial versican is significantly associated with lymph node metastasis in endometrial and cervical cancer $(32,40)$. The role of cancer cell-associated versican appears to be specific to the type of cancer. Further studies are required to clarify the mechanism and functional role of epithelial versican expression.

Our study shows that loss of epithelial syndecan-1 expression and stromal syndecan-1 and versican expression is associated with reduced survival in patients with epithelial ovarian cancer. In our previous study, we showed that stromal syndecan-1 and versican expression are independent prognostic factors in endometrial cancer $(17,32)$. However, stromal syndecan-1 and versican expression was not a statistically significant prognostic factor for survival of epithelial ovarian cancer patients, although negative syndecan-1 expression was an independent prognostic factor for progression-free survival.

In conclusion, loss of epithelial syndecan-1 expression and induction of stromal syndecan-1 and versican expression may be associated with tumor progression in epithelial ovarian cancer. Our findings also provide evidence that syndecan-1 and versican expression status can serve as an indicator of prognosis in patients with epithelial ovarian cancer.

\section{References}

1. Kresse H and Schonherr E: Proteoglycans of the extracellular matrix and growth control. J Cell Physiol 189: 266-274, 2001 . 
2. Bernfield M, Gotte M, Park PW, et al: Functions of cell surface heparan sulfate proteoglycans. Annu Rev Biochem 68: 729-777, 1999.

3. Yanagishita M and Hascall VC: Cell surface heparan sulfate proteoglycans. J Biol Chem 267: 9451-9454, 1992.

4. Carey DJ: Syndecans: multifunctional cell-surface corecepters. Biochem J 327: 1-16, 1997.

5. Bernfield M, Kokenyesi R, Kato M, et al: Biology of syndecans. Annu Rev Cell Biol 8: 365-393, 1992.

6. Sanderson RD, Hinkes M and Bernfield M: Syndecan-1, a cell surface proteoglycan, changes in size and abundance when keratinocytes stratify. J Invest Dermatol 99: 390-396, 1992.

7. Liebersbach BF and Sanderson RD: Expression of syndecan-1 inhibits cell invasion into type I collagen. J Biol Chem 269: 20013-20019, 1994

8. Leppa S, Mali M, Miettinen HM, et al: Syndecan expression regulates cell morphology and growth of mouse mammary epithelial tumor cells. Proc Natl Acad Sci USA 189: 932-936, 1992.

9. Inki P, Stenback F, Talve L, et al: Immunohistochemical localization of syndecan in mouse skin tumors induced by UV irradiation. Loss of expression associated with malignant transformation. Am J Pathol 139: 1333-1340, 1991.

10. Fujiya M, Watari J, Ashida T, et al: Reduced expression of syndecan-1 affects metastatic potential and clinical outcome in patients with colorectal cancer. Jpn J Cancer Res 92: 1074-1081, 2001 .

11. Wiksten JP, Lundin J, Nordling S, et al: Epithelial and stromal sundecan-1 expression as predictor of outcome in patients with gastric cancer. Int J Cancer 95: 1-6, 2001.

12. Anttonen A, Kajanti M, Heikkila P, et al: Syndecan-1 expression has prognostic significance in head and neck carcinoma. $\mathrm{Br}$ J Cancer 79: 558-564, 1999.

13. Klatka J: Syndeca-1 expression in laryngeal cancer. Eur Arch Otorhinolaryngol 259: 115-118, 2002.

14. Stah L, Walter KL, Borczuk AC, et al: Expression of syndecan-1 and expression of epidermal growth factor receptor are associated with survival in patients with non-small cell lung carcinoma Cancer 101: 1632-1638, 2004.

15. Harada K, Masuda S, Hirano M, et al: Reduced expression of syndecan-1 correlates with histologic dedifferentiation, lymph node metastasis, and poor prognosis in intrahepatic cholangiocarcinoma. Hum Pathol 34: 857-863, 2003.

16. Kumar-Singh S, Jacobs W, Dhaene K, et al: Syndecan-1 expression in malignant mesothelioma: correlation with cell differentiation, WT1 expression, and clinical outcome. J Pathol 186: 300-305, 1998.

17. Hasengaowa, Kodama J, Kusumoto T, et al: Prognostic significance of syndecan-1 expression in human endometrial cancer. Ann Oncol 16: 1109-1115, 2005.

18. Leivonen M, Lundin J, Nordling S, et al: Prognostic value of syndecan-1 expression in breast cancer. Oncology 67: 11-18, 2004.

19. Máthé M, Suba Z, Németh Z, et al: Stromal syndecan-1 expression is an adverse prognostic factor in oral carcinomas. Oral Oncol 42: 493-500, 2006.

20. Schwartz NB, Pirok EW III, Maensch JR Jr, et al: Domain organization, genomic structure, evolution, and regulation of expression of the aggrecan gene family. Proc Nucleic Acid Res Mol Biol 62: 177-223, 1999.

21. Dours-Zimmermann MT and Zimmermann DR: A novel glycosaminoglycan attachment domain in identified in two alternative splice variants of human versican. J Biol Chem 269: 32992-3298, 1994.

22. Ito K, Shinomura T, Zako M, et al: Multiple forms of mouse PG-M, a large chondroitin sulfate proteoglycans generated by alternative splicing. J Biol Chem 270: 958-965, 1995.

23. Zako M, Shinomura T, Ujita M, et al: Expression of PG-M (V3), an alternatively spliced form of PG-M without a chondroitin sulfate attachment in region in mouse and human tissues. J Biol Chem 270: 3914-3918, 1995.
24. Theocharis AD, Tsara ME, Papageorgacopoulou N, et al: Pancreatic carcinoma is characterized by elevated content of hyaluronan and chondroitin sulfate with altered disaccharide composition. Biochim Biophys Acta 1502: 201-206, 2000.

25. Theocharis AD: Human colon adenocarcinoma is associated with specific post-translational modifications of versican and decorin. Biochim Biophys Acta 1588: 165-172, 2002.

26. Skandalis S, Theocharis AD, Theocharis DA, et al: Matrix proteoglycans are markedly affected in advanced laryngeal squamous cell carcinoma. Biochim Biophys Acta 1689: 152-161, 2004.

27. Sakko AJ, Ricciardelli C, Mayne K, et al: Versican accumulation in human prostatic fibroblast cultures is enhanced by prostate cancer cell-derived transforming growth factor beta1. Cancer Res 61: 926-930, 2001.

28. Suwiwat S, Ricciardelli C, Tammi R, et al: Expression of extracellular matrix components versican, chondroitin sulfate, tenascin, and hyaluronan, and their association with disease outcome in node-negative breast cancer. Clin Cancer Res 10: 2491-2498, 2004.

29. Pirinen R, Leinonen T, Böhm J, et al: Versican in non-small cell lung cancer: relation to hyaluronan, clinicopathologic factors, and prognosis. Human Pathol 36: 44-50, 2005.

30. Ricciardelli C, Mayne K, Sykes PJ, et al: Elevated levels of versican but not decorin predict disease progression in earlystage prostate cancer. Clin Cancer Res 4: 963-971, 1998.

31. Pukkila M, Kosunen A, Ropponen K, et al: High stromal versican expression predicts unfavorable outcome in oral squamous cell carcinoma. J Clin Pathol 60: 267-272, 2006.

32. Kodama J, Hasengaowa, Kusumoto T, et al: Prognostic significance of stromal versican expression in human endometrial cancer. Ann Oncol 18: 269-274, 2007.

33. Ruoslahti E: Integrins. J Clin Invest 87: 1-5, 1991.

34. Takeichi M: Cadherin cell adhesion receptors as a morphogenetic regulator. Science 251: 1451-1455, 1991 .

35. Wight T, Kinsella MG and Qwarnstrom EE: The role of proteoglycans in cell adhesion, migration and proliferation. Curr Opin Cell Biol 4: 793-801, 1992.

36. Davies EJ, Blackhall FH, Shanks JH, et al: Distribution and clinical significance of heparin sulfate proteoglycans in ovarian cancer. Clin Cancer Res 10: 5178-5186, 2004.

37. Kato M, Saunders S, Nguyen H, et al: Loss of cell surface syndecan-1 causes epithelia to transform into anchorageindependent mesenchyme-like cells. Mol Biol Cell 6: 559-576, 1995.

38. Stanley MJ, Staley MW, Sanderson RD, et al: Syndecan-1 expression is induced in the stroma of infiltrating breast carcinoma. Am J Clin Pathol 112: 377-383, 1999.

39. Maeda T, Alexander CM and Friedl A: Induction of syndecan-1 expression in stromal fibroblasts promotes proliferation of human breast cancer cell. Cancer Res 64: 612-621, 2004.

40. Kodama J, Hasengaowa, Kusumoto T, et al: Versican expression in human cervical cancer. Eur J Cancer 43: 1460-1466, 2007.

41. Hanekamp EE, Gielen SCJP, Smid-Koopman E, et al: Consequence of loss of progesterone receptor expression in development of invasive endometrial cancer. Clin Cancer Res 9: 4190-4199, 2003.

42. Ang LC, Zang Y, Cao L, et al: Versican enhances locomotion of astrocytoma cells and reduces cell adhesion through its G1 domain. J Neuropathol Exp Neurol 58: 597-605, 1999.

43. Yang BL, Zhang Y, Cao L, et al: Cell adhesion and proliferation mediated through the $\mathrm{G} 1$ domain of versican. J Cell Biochem 72: 210-220, 1999.

44. Casey RC, Oegema TR Jr, Skubitz KM, et al: Cell membrane glycosylation mediate the adhesion, migration, and invasion of ovarian carcinoma cells. Clin Exp Metastasis 20: 143-152, 2003.

45. Voutilainen K, Anttila M, Sillanpaa S, et al: Versican in epithelial ovarian cancer: relation to hyaluronan, clinicopathologic factors and prognosis. Int J Cancer 107: 359-364, 2003. 